\title{
Proposta de Ensino de Produção de Texto Dissertativo-Argumentativo pela Teoria dos Blocos Semânticos
}

\begin{abstract}
A Teaching Proposal of Production of Dissertative-Argumentative Texts Based on the Theory of Semantic Blocks
\end{abstract}

\section{Cláudio Primo Delanoy* Lauro Gomes**}

Resumo: Este trabalho propõe-se a explicitar uma proposta de ensino de produção de texto dissertativo-argumentativo, com base em conceitos e princípios da teoria da Argumentação na Língua (ADL), de Ducrot (1990, 2009), e, sobretudo, em ferramentas postas à disposição pela Teoria dos Blocos Semânticos (TBS), de Carel (1995, 2005), e Carel e Ducrot (2005). Para tanto, analisa-se, primeiramente, a proposta de redação do Enem 2012, com vistas a encontrar as unidades semânticas básicas de seus textos motivadores, as quais, ao serem associadas a aspectos argumentativos de blocos semânticos que as originam, podem, a partir das relações semânticas existentes dentro de um mesmo bloco, orientar percursos argumentativos eficazes a serem realizados no texto dissertativo-argumentativo. Verifica-se, ademais, em que medida os encadeamentos argumentativos transgressivos apresentam-se, em redações argumentativas, como mais convincentes do

* Doutor em Linguística (2008) e Pós-doutorando em Linguística pela Pontifícia Universidade Católica do Rio Grande do Sul (bolsista DOCFIX FAPERGS/CAPES). Professor da Pontifícia Universidade Católica do Rio Grande do Sul. Contato: claudio.delanoy@pucrs.br.

** Mestre em Letras (2014) e Doutorando em Letras pela Universidade de Passo Fundo (bolsista PROSUP/CAPES). Professor substituto do Instituto Federal de Educação, Ciência e Tecnologia do Rio Grande do Sul. Professor do Colégio Franciscano São José de Erechim. Contato: lauro.20@bol.com.br. 
que os encadeamentos argumentativos normativos. Em vista disso, este trabalho poderá fornecer subsídios teórico-metodológicos aos professores que trabalham diretamente com o ensino de leitura e produção de textos, tanto na educação básica como na superior.

Palavras-chave: Bloco semântico. Ensino. Texto dissertativo-argumentativo.

Abstract: This paper aims to explain a teaching proposal of production of dissertative-argumentative texts, based on concepts and principles of the Theory of Argumentation within Language (ADL) of Ducrot (1990, 2009), and above all in tools made available by the Theory of Semantic Blocks (TBS), Carel $(1995,2005)$, and Carel and Ducrot (2005). In order to do so, first, the text production proposal of Enem 2012 is analyzed, so as to find the basic semantic units of its motivational texts, which, by being associated to argumentative aspects of semantic blocks that originate those semantic units, may guide effective argumentative routes to be realized in dissertativeargumentative text from semantic relations within the same block. It is verified, also, to what extent argumentative transgressive chaining are presented in argumentative essays as more convincing than the normative argumentative ones. As a result, this work may provide theoretical and methodological support for teachers that have been working directly with the teaching of reading and writing, in basic or superior education levels.

Keywords: Semantic block. Teaching. Dissertative-argumentative text.

\section{Introdução}

O tema deste trabalho surge a partir da demanda por estudos relacionados ao ensino de produção de textos dissertativo-argumentativos, que disponham de subsídios teóricos capazes de auxiliar estudantes a, por exemplo, ler um texto e discernir ideias principais de secundárias, a fazer delimitações e a elaborar projetos eficazes de redação, uma vez que essas atividades são essenciais para qualquer estudante que busca ter sucesso acadêmico. 
Uma pesquisa dessa natureza se justifica na medida em que, ao se observarem os resultados de avaliações externas - como do Exame Nacional do Ensino Médio (Enem) e do Exame Nacional de Desempenho de Estudantes (Enade), tem sido possível constatar grande insucesso de alunos concluintes da educação básica e também da superior em tarefas que envolvem leitura e produção de textos, diagnóstico este que também instala a necessidade de revisão teórica de práticas de ensino dessas duas grandes competências.

Diante disso, partindo do princípio de que a proposta de redação e a redação produzida nos padrões formais de texto dissertativo-argumentativo são dois gêneros de uma mesma interação, como destacam Graeff e Gomes $(2012)^{1}$, pretende-se, com este estudo, explicitar em que medida as propostas de redação, aos moldes das do Enem, dispõem, em seus textos motivadores, de percursos argumentativos possíveis de serem seguidos pelo estudante, em sua redação, permitindo que se utilizem não apenas argumentações normativas, aquelas construídas por portanto, mas também, e sobretudo, argumentações transgressivas, aquelas construídas por mesmo assim.

Para tanto, com base em conceitos e princípios da teoria da Argumentação na Língua (ADL)², de Ducrot (1990, 2009), especialmente na versão da Teoria dos Blocos Semânticos (TBS), segundo Carel (1995, 2005) e Carel e Ducrot (2005), analisam-se os textos motivadores que compõem a proposta de redação do Enem 2012, a fim de encontrar as unidades semânticas básicas que os resumem, visto que, após serem associadas aos aspectos argumentativos dos blocos semânticos que as originam, é possível explicitar percursos argumentativos aceitáveis e eficientes, a partir do que orienta a proposta.

Cumpre salientar que, se o ensino de leitura e de escrita passar a ser melhor fundamentado teoricamente, acredita-se na possibilidade de os alunos começarem a apresentar estratégias linguístico-discursivas capazes de deixar

${ }^{1}$ Conforme Graeff e Gomes, baseados em Bakhtin e seguidores, a proposta de redação pode ser entendida como um novo gênero textual, visto que, com a publicação do Guia do Participante do Enem, em 2012 e em 2013, estabilizaram-se as suas características de forma estilo, estrutura composicional e conteúdo temático.

2 ADL é a sigla do nome da teoria em francês: « l'Argumentation Dans la Langue ». 
marcas de autoria e, por conseguinte, de lhes permitir evitar o uso de pensamentos genéricos, de senso comum, em seus escritos. Em vista disso, na sequência deste trabalho, explicitam-se fundamentos teóricos da ADL/TBS, a respeito do funcionamento da construção semântico-argumentativa de entidades linguísticas (palavra, enunciado, discurso), para, em seguida, realizar a análise do corpus e apontar as considerações finais, que, à luz da teoria aqui utilizada, também apresentam a concessão como uma estratégia argumentativa eficaz de se utilizar em textos dissertativo-argumentativos.

\section{A Construção do Sentido para a Teoria da Argumentação na Língua}

A teoria da Argumentação na Língua (ADL) é uma teoria semântica que concebe o sentido de um enunciado como sendo construído pelas entidades linguísticas postas em relação. Diferentemente das concepções referencialistas da linguagem, que veem o sentido atrelado aos objetos no mundo real, a ADL vincula-se ao princípio saussuriano de estudar a língua por meio de suas relações internas. Assim como o signo linguístico que, segundo Saussure, não é definido por si mesmo, mas sim pela oposição que faz em relação aos outros signos (valor do signo linguístico), na perspectiva da ADL, é somente no discurso que as palavras produzem sentido, isto é, quando são relacionadas entre si. Esse princípio está de acordo com a Nota sobre o discurso, nos Escritos de Lingüistica Geral (SAUSSURE, 2004, p. 237): fora do uso, as palavras têm conceitos isolados que "esperam ser postos em relação entre si para que haja significação de pensamento". Desse modo, percebe-se a relevância do conceito de relação entre entidades linguísticas para a produção de sentido. Por exemplo: a expressão o restaurante está cheio assume um sentido próprio quando articulada a uma conclusão, como portanto é de boa qualidade. Trata-se de um restaurante convidativo, bastante apreciado, por isso é bastante frequentado. Por outro lado, se o restaurante está cheio for articulado a portanto deve ser barato, seu sentido será alterado: passa a ser um local bem frequentado por ter preços populares. Vê-se, então, que uma expressão assume sentidos distintos dependendo da continuação discursiva que a ela se dá. É devido a essa interdependência semântica que, segundo postula a ADL, o sentido é argumentativo. 
Ducrot explica a natureza argumentativa da língua, em contraste com uma suposta natureza informativa, ao analisar, por exemplo, o sentido das expressões ponco e um ponco. Segundo o linguista, a escolha de ele comen ponco ou ele comeu um pouco, ao referir-se à quantidade de alimento ingerido por uma pessoa, não tem valor informativo, mas argumentativo. De fato, é a continuação do discurso do locutor que determinará o uso da expressão ponco ou um ponco: se o locutor quiser continuar seu discurso com então ele não vai melhorar, deverá decidir-se por ele comen ponco; por outro lado, se quiser dizer então ele vai melhorar, a escolha será por ele comeu um pouco. Com esse exemplo, Ducrot afirma que o sentido de uma expressão linguística depende da sua continuação no discurso, e não de informações decorrentes do mundo extralinguístico.

Além de estudar a língua em suas relações internas, a ADL também buscou em Saussure a concepção de ver na linguagem uma face concreta e outra abstrata, interdependentes. Ducrot (1984, p. 368) identifica dois elementos distintos na produção de linguagem. Um deles é o material linguístico empregado, de caráter abstrato, pertencente ao sistema da língua. Outro são as diversas realizações desse material, distintas entre si em termos de pessoa (no sentido gramatical), de tempo e de espaço. A partir dessa diferenciação, definem-se frase, texto, enunciado e discurso. Frase é o material linguístico usado pelo locutor, um construto teórico, enquanto texto designa um conjunto de frases, ambos de natureza abstrata. Denomina enunciado a realização da frase, quer dizer, o que foi efetivamente produzido. O discurso, por sua vez, é um conjunto de enunciados inter-relacionados, o que resulta ser a concretização de um texto.

Assim como frase e enunciado têm naturezas diferentes (abstrata e concreta, respectivamente), seus valores semânticos também devem ser distinguidos. As frases são dotadas de significação e os enunciados têm sentido. Essa separação se justifica devido ao sentido ser produzido a partir do uso da língua, não havendo a ideia de um sentido constante. A significação, por outro lado, é constituída de instruções abertas, gerais, amplas, que vão direcionar a produção do sentido no uso da língua. Logo, é no uso da língua que os falantes constroem o sentido do enunciado.

A ADL também é uma teoria enunciativa. Isso significa admitir a presença de um locutor responsável pela produção linguística num determinado 
tempo e espaço, direcionada a um alocutário. As pessoas denominadas locutor e alocutário não devem ser confundidas com os seres reais, individualizados no mundo, mas seres discursivos, que ganham esse estatuto pela própria instância enunciativa. O locutor tem responsabilidade de seu enunciado e nele se marca em termos de pessoa, tempo e espaço ao produzir eu, agora e aqui.

O locutor, ao produzir um enunciado, põe as entidades linguísticas em relação. Desse modo, revela sua subjetividade, ou, em termos da ADL, ele argumenta. Para a ADL, argumentar é pôr em relação dois segmentos ligados por um conector. Como exemplo, cita-se o encadeamento Maria é uma profissional competente, portanto terá êxito no novo emprego. Observa-se a argumentação: ao encadear profissional competente com êxito no novo emprego, o locutor produz o sentido de a competência profissional resulta em êxito na carreira. Se produzisse Maria é uma profissional competente, portanto saberá solucionar oproblema, o sentido seria a competência profissional possibilita a resolução de problemas.

Como se pode depreender, a argumentação é a expressão da subjetividade do locutor, de um ponto de vista, ao encadear dois segmentos de discurso. É o locutor que toma a realidade como um tema e a partir dele argumenta ao produzir linguagem. Dessa forma, a ADL localiza a argumentação no próprio sistema linguístico, ao afirmar que as expressões da língua já carregam em si uma orientação argumentativa para a continuação do discurso. Logo, a argumentação não está nos fatos do mundo, mas está na natureza da língua. A Teoria dos Blocos Semânticos, inscrita na ADL, revela essa essência argumentativa.

Ferramentas da Teoria dos Blocos Semânticos para leitura e produção de textos

A Teoria dos Blocos Semânticos, postulada por Marion Carel em 1992, radicaliza as ideias que fundam a ADL, uma vez que defende que o sentido de uma expressão qualquer, seja ela uma palavra ou um enunciado, está constituído pelos encadeamentos argumentativos, isto é, discursos que essa expressão evoca. Entende-se por encadeamento argumentativo o encadeamento entre dois segmentos que têm a forma de X CONECTOR Y; e, segundo Carel e Ducrot (2005), a TBS reconhece apenas dois tipos de conectores: os normativos, que são do tipo de donc, constituídos por portanto, e os transgressivos, que são do tipo de pourtant, constituídos por mesmo assim. 
É importante destacar que a oposição normativo e transgressivo se encontra no interior de palavras, inclusive daquelas que não parecem ter, em absoluto, essa significação. Note-se que a diferença entre as expressões $I h$ ! e É claro, em enunciados como (1) Ih! Pedro está ali. e (2) É claro, Pedro está ali., representa-se mediante a oposição normativo/ transgressivo. Conforme Carel e Ducrot, (2005), dizendo Ih! Pedro está ali, deve-se entender que há razões para se pensar que ele não deveria estar ali. Logo, pode-se evocar desse enunciado o encadeamento argumentativo transgressivo X mesmo assim Pedro está ali. Dizendo, todavia, É claro, Pedro está ali, deve-se entender que haveria razões para se pensar que Pedro estaria ali. Evoca-se, em vista disso, o encadeamento argumentativo normativo $X$ portanto Pedro está ali. Conforme notam os semanticistas citados, a distinção entre mesmo assim e portanto se estende por toda a língua.

Como se não bastasse, nas palavras de Carel (2005, p. 81), "Essa oposição de normativo e transgressivo é, para mim, um fenômeno lingüístico profundo, que não se realiza unicamente na oposição dos morfemas específicos donc e pourtant'. Esclarece a referida semanticista que, no discurso proferido por um prefeito, Eu defenderei os interesses dos que votaram em mim, mas também dos que votaram contra mim, a permuta não é possível, salvo expressão irônica. Note-se que, do discurso Eu defenderei os interesses dos que votaram contra mim, mas também dos que votaram em mim, evoca-se, à esquerda, o discurso transgressivo Eles votaram contra mim, mesmo assim eu os defenderei e, à direita, evoca-se o discurso normativo Eles votaram em mim, portanto eu os defenderei. De acordo com Carel (2005), X mas também Y assinala que os segmentos X e Y contêm discursos complexos, uma vez que "mas também" assinala que $\mathrm{X}$, à esquerda, contém um discurso normativo e que $\mathrm{Y}$, à direita, contém um discurso transgressivo. Seguindo nessa direção, vale salientar que, ao conjunto de encadeamentos argumentativos, convencionou-se chamar aspecto. Para melhor explicitar esse conceito, observe-se que um aspecto normativo como A DC (= portanto) B conterá, entre outros encadeamentos, (1) O hotel está perto da Universidade, portanto é fácil chegar, (2) A Catedral está perto da Faculdade, portanto é fácil chegar e, igualmente, (3) Meu dormitório está perto do teu, portanto é fácil chegar, visto que, em todos esses casos, o pertinente é A, perto, e B, fácil chegar. 
Para análises textuais, como as que são feitas neste trabalho, convém tomar, também, o que afirma Carel (2012), ao postular que uma parte do texto constitui um motivo argumentativo se, ao mesmo tempo, ela exprime um aspecto argumentativo e evoca um encadeamento argumentativo. Para exemplificar, observe-se o fragmento do início do livro Claude Gueux, de Victor Hugo (apud GRAEFF, 2012, p. 198, grifos do autor):

Um inverno, o trabalho faltou. Nada de fogo nem de pão no sótão. O homem, a moça e a criança passaram frio e fome. O homem roubou. Eu não sei o que ele roubou, en não sei onde ele roubou. O que en sei, é que desse roubo resultaram trếs dias de pão e de fogo para a mulher e a criança, e cinco anos de prisão para o homem.

Notadamente, o principal encadeamento argumentativo que esse trecho permite evocar é roubou pequena quantidade mesmo assim sofreu grande punição, ao qual se pode associar o aspecto argumentativo PEQUENO DELITO PT GRANDE PUNIÇÃO, que pode ser a argumentação interna $(\mathrm{AI})^{3}$ de injustiça. Em vista disso, tem-se, nesse trecho, um julgamento argumentativo completo ou um motivo argumentativo.

Depois de explicitadas essas noções preliminares, cumpre realçar que o bloco semântico surge da interpendência semântica que se estabelece entre A e B. Abaixo, pode-se verificar um quadrado argumentativo, dentro do qual se estabelecem relações semânticas diferentes entre os quatro aspectos argumentativos. Confiram-se:

Segundo Carel e Ducrot (2005), a argumentação interna (AI) de uma entidade linguística palavra, enunciado, discurso está constituída por um certo número de aspectos aos quais pertencem os encadeamentos que parafraseiam essa entidade. 
(1) A PT NEG-B

(3) NEG-A DC

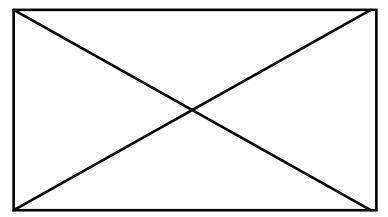

(2) NEG-A PT B

(4) A DC B

NEG-B

Fonte: Os autores.

Figura 1 - Quadrado Argumentativo

Destaque-se que as relações que se estabelecem entre (1) e (2) e (3) e (4) são de reciprocidade, entre (1) e (4) e (2) e (3) são de conversão e entre (1) e (3) e (2) e (4) são de transposição. No entanto, é fundamental que se compreenda que, diferentemente do que ocorre no quadrado aristotélico, por exemplo em que as relações estabelecidas entre as expressões que aparecem nos quatro cantos do quadrado são relações lógicas, no quadrado argumentativo proposto pela TBS as relações entre os aspectos não são lógicas, mas discursivas. Nas palavras de Carel e Ducrot (2005, p. 45, tradução nossa), "Desnecessário seria dizer que na teoria que construímos não podemos fazer intervir este tipo de relações nem a noção de verdade, já que a verdade se define pelos vínculos entre um enunciado e a realidade"4.

Nesse sentido, Ducrot (2009) afirma que a TBS toma a palavra argumentação num sentido não habitual que leva a muitos mal-entendidos, pois é comum que a argumentação linguística, a que se propõe estudar, seja confundida com a argumentação retórica, oriunda dos estudos aristotélicos. Segundo Ducrot (2009, p. 20), entende-se por argumentação retórica "a atividade verbal que visa a fazer alguém crer em alguma coisa. Essa atividade é de fato um dos objetos de estudo tradicionais da retórica". Por argumentação linguística, ao contrário, entende-se o encadeamento de duas

${ }^{4}$ De más está decir que en la teoría que construimos no podemos hacer intervenir este tipo de relaciones ni la noción de verdad, ya que la verdad se define por los vínculos entre un enunciado y la realidad. 
proposições A e C ligadas, implícita ou explicitamente, por um conector do tipo donc (portanto). Nas palavras de Ducrot (2009, p. 21), "Essa definição pode ser estendida aos encadeamentos que ligam, não duas proposições sintáticas, mas duas sequências de proposições, por exemplo, dois parágrafos de um artigo".

De acordo com Ducrot (2009), a Retórica Tradicional exige que não somente se deem razões que constituem o que se chama de logos, mas que se desenvolva, no ouvinte, o desejo de crer verdadeiro (pathos) e, enfim, confiese no orador, que deve aparecer como confiável, sério, bem intencionado, dando uma imagem favorável de si mesmo (ethos). Para diferenciar a argumentação retórica da argumentação linguística, Ducrot (2009) também afirma que a argumentação discursiva não tem nenhum caráter racional, que ela não fornece justificação, nem mesmo esboços fracos, lacunares, de justificação. É exatamente em função disso que o portanto é um meio de descrever e não de provar, de justificar, de tornar verossímil.

Para mostrar como existe argumentação linguística até mesmo na argumentação retórica, Ducrot (2009) defende que a argumentatividade está ligada à concessão, que é uma estratégia tida como eficaz. Descreve-a, portanto, do seguinte modo:

Suponhamos que um locutor queira fazer admitir uma conclusão Z. Suponhamos também que ele disponha de um argumento $Y$ que permite encadear $Y$ portanto $Z$, mas que ele saiba, além disso, que há argumentos $\mathrm{X}$ que permitem encadear $\mathrm{X}$ portanto não-Z. Assim, eu quero levar um amigo à conclusão $\mathrm{Z}=$ tu não deves fumar. Para isso, eu disponho entre outros de um argumento $\mathrm{Y}=$ fumar te faz tossir, mas eu sei também que os fumantes têm um argumento $\mathrm{X}=$ fumar diminui o stress, que pode ser encadeado por portanto à conclusão não- $Z=$ não se deve parar de fumar. (DUCROT, 2009, p. 24, grifos do autor).

Note-se que, na situação 1, tem-se: (L1) Fumar te faz tossir DC NÃO FUMAR, em que (L2) poderia responder: Sim, mas diminui o stress DC FUMAR. $\mathrm{Na}$ segunda situação, ter-se-ia: Fumar diminui o stress, mas te faz tossir DC NÃO FUMAR. Notadamente, indicando $\mathrm{X}$, que é desfavorável à tese defendida por (L1), e favorável à tese do interlocutor (L2), pode-se impedir L2 de 
utilizar X. Nas palavras de Ducrot (2009, p. 24), "A essa vantagem da concessão para a estratégia polêmica, acrescento o fato de que ela permite melhorar a imagem que o orador dá de si em seu discurso".

Diante disso, pode-se afirmar que ensinar essa estratégia argumentativa de concessão a estudantes do ensino médio e da educação superior pode ser um meio eficaz de auxiliá-los na construção de textos dissertativo-argumentativos mais eficientes, isto é, textos que fujam às ideias de senso comum e à cópia e/ou à paráfrase dos textos da proposta de redação. Nesse sentido, na sequência deste trabalho, analisa-se a proposta de redação do Enem 2012, a fim de explicitar as orientações argumentativas autorizadas pelos textos que a compõem, e para sugerir um percurso argumentativo que teria sido possível de ser seguido pelo estudante em seu texto dissertativo-argumentativo.

\section{Metodologia e Análise do corpus}

Com base nos princípios e conceitos explicitados ao longo da fundamentação teórica, especialmente dos que são postos à disposição pela TBS, realiza-se, aqui, a análise da proposta de redação do Enem 2012, publicada em $A$ redação no Enem 2013: Guia do Participante (INEP, 2013). A metodologia utilizada seguiu, para tanto, os seguintes passos: (1) os textos motivadores foram reduzidos às suas unidades semânticas básicas, isto é, aos encadeamentos argumentativos em DC (= portanto) ou em PT (= mesmo assim) que os resumem; (2) a cada encadeamento argumentativo evocado associou-se o aspecto argumentativo do bloco semântico que o origina; e (3) explicitou-se um percurso argumentativo aceitável, a partir da proposta de redação, o qual resulta num plano de texto que vai além do senso comum, posto que, além de reconhecer a existência da norma, permite transgredi-la.

Vale destacar que essa proposta de redação é composta por um trecho inicial que, além de orientar o estudante em relação ao gênero em que deverá organizar seu texto, dissertativo-argumentativo, e de explicitar o tema para redação, O movimento imigratório para o Brasil no século XXI, também fornece instruções sobre o estilo de linguagem a ser utilizado no texto, a norma padrão da lingua portuguesa, e sobre a importância de se apresentar uma proposta de intervenção, que respeite os direitos humanos. Ademais, o primeiro trecho instrui o aluno 
a selecionar, organizar e relacionar, de forma coerente e coesa, argumentos e fatos para defesa de seu ponto de vista.

Seguem, posteriormente, três textos contendo apenas linguagem verbal e um texto contendo linguagem verbal e não verbal, o qual, por meio de flechas sobre o mapa da América Latina, explicita a rota da migração dos haitianos para o Brasil. Confiram-se, a seguir, os textos motivadores contendo apenas linguagem verbal e as análises:

Ao desembarcar no Brasil, os imigrantes trouxeram muito mais que o anseio de refazer suas vidas trabalhando nas lavouras de café e no início da indústria paulista. Nos séculos XIX e XX, os representantes de mais de 70 nacionalidades e etnias chegaram com o sonho de 'fazer a América' e acabaram por contribuir expressivamente para a história do país e para a cultura brasileira. Deles, o Brasil herdou sobrenomes, sotaques, costumes, comidas e vestimentas.

A história da migração humana não deve ser encarada como uma questão relacionada exclusivamente ao passado; há a necessidade de tratar sobre deslocamentos mais recentes. [...] (GUIA DO ESTUDANTE, 2014).

Desse discurso pode-se evocar, primeiramente, o encadeamento argumentativo normativo [desembarcarem imigrantes de mais de 70 nacionalidades no Brasil, nos séculos XIX e XX, portanto "fazer a América"], ao qual é possível associar o aspecto argumentativo IMIGRAR DC DESENVOLVER. Note-se que esse encadeamento apresenta a imigração dos séculos XIX e XX como positiva para o Brasil, posto que permitiu "fazer a América", ou seja, permitiu expandi-la. Como se não bastasse, o encadeamento seguinte explicita melhor o sentido de sonho de "fazer a América". Confira-se: [disposição para construir a América, portanto contribuição para a história do país e para a cultura brasileira], ao qual se pode associar o aspecto TRABALHAR DC CONTRIBUIR.

Por fim, pode-se evocar uma estrutura de $\mathrm{X}$ mas também $\mathrm{Y}$, que, conforme Carel (2005), assinala segmentos contendo discursos complexos, visto que $\mathrm{X}$, à esquerda, contém um discurso normativo e $\mathrm{Y}$, à direita, contém um discurso transgressivo. Nesse texto em análise, a estrutura evocada pode 
ser representada da seguinte forma: [a história da migração humana deve ser encarada não só como uma questão relacionada ao passado mas também ao presente, tratando sobre deslocamentos recentes]. Desmembrando-se os segmentos, ter-se-ia, à esquerda, o discurso normativo [é migração humana relacionada ao passado, portanto deve ser encarada] e, à direita, ter-se-ia o discurso transgressivo [é migração humana relacionada ao presente, mesmo assim deve ser encarada]. Em função disso, a construção inversa resultaria estranha. Observe-se: [* a história da migração humana deve ser encarada não só como uma questão relacionada ao presente mas também ao passado].

Chega-se à conclusão de que esse texto, por meio dos aspectos argumentativos IMIGRAR DC DESENVOLVER e TRABALHAR DC CONTRIBUIR, argumenta positivamente à imigração dos séculos XIX e $\mathrm{XX}$, e, por meio da estrutura implícita de X mas também Y, chama a atenção para os deslocamentos que vêm acontecendo atualmente, no Brasil. Entretanto, essa não é a mesma argumentação constituída pelo texto a seguir. Leia-se:

\section{Acre sofre com invasão de imigrantes do Haiti}

Nos últimos três dias de 2011, uma leva de 500 haitianos entrou ilegalmente no Brasil pelo Acre, elevando para 1400 a quantidade de imigrantes daquele país no município de Brasileia (AC). Segundo o secretário-adjunto de Justiça e Direitos Humanos do Acre, José Henrique Corinto, os haitianos ocuparam a praça da cidade. A Defesa Civil do estado enviou galões de água potável e alimentos, mas ainda não providenciou abrigo.

A imigração ocorre porque o Haiti ainda não se recuperou dos estragos causados pelo terremoto de janeiro de 2010. O primeiro grande grupo de haitianos chegou a Brasileia no dia 14 de janeiro de 2011. Desde então, a entrada ilegal continua, mas eles não são expulsos: obtêm visto humanitário e conseguem tirar carteira de trabalho e CPF para morar e trabalhar no Brasil.

Segundo Corinto, ao contrário do que se imagina, não são haitianos miseráveis que buscam o Brasil para viver, mas pessoas da classe média do Haiti e profissionais qualificados, como engenheiros, professores, advogados, pedreiros, mestres de obras e carpinteiros. Porém, a maioria chega sem dinheiro. 
Os brasileiros sempre criticaram a forma como os países europeus tratavam os imigrantes. Agora, chegou a nossa vez afirma Corinto. [...] (GUIA DO ESTUDANTE, 2014).

Esse segundo texto motivador permite evocar, de início, o encadeamento argumentativo normativo [entrar ilegalmente no Brasil uma leva de 500 haitianos, portanto elevar para 1.400 a quantidade de imigrantes no Acre], ao qual se pode associar o aspecto argumentativo IMIGRAR ILEGALMENTE DC AUMENTAR POPULAÇÃO. Observe-se que o sentido que esse encadeamento constrói é de uma imigração negativa para o Brasil.

A seguir, o encadeamento argumentativo transgressivo evocado é [Enviar galões de água potável e alimentos, mesmo assim não providenciar abrigo], cujo aspecto expresso é VIABILIZAR ÁGUA E ALIMENTO PT NEG-PROVIDENCIAR ABRIGO, que, nesse caso, constitui uma AI de negligência. $\mathrm{Na}$ sequência do discurso, explicita-se a causa da imigração dos haitianos, de cujo trecho é possível evocar o encadeamento argumentativo normativo [não ter se recuperado de estragos causados por terremoto, portanto imigrar], ao qual se associa o aspecto ESTAR DESESTRUTURADO DC IMIGRAR.

O encadeamento evocado posteriormente é [entrar ilegalmente no Brasil, mesmo assim não ser expulso], ao qual se pode associar o aspecto INFRINGIR NORMAS PT NEG-RECEBER PUNIÇÃO. Note-se, aqui, que esse encadeamento reitera a AI de negligência e alude à Defesa Civil, órgão brasileiro responsável pelo controle de entrada de estrangeiros no país. $\mathrm{Na}$ sequência do discurso, evocam-se encadeamentos que revelam parte do perfil socioeconômico dos haitianos. O primeiro da sequência, [ser haitiano, portanto ser miserável], tem como aspecto expresso HAITIANO DC MISERÁVEL. O princípio argumentativo por ele relacionado é, porém, transgredido a seguir, por meio do encadeamento [ser haitiano, mesmo assim ser pessoa da classe média com qualificação], ao qual se associa o aspecto SER HAITIANO PT POSSUIR QUALIFICAÇÃO.

Por fim, evocam-se os encadeamentos argumentativos transgressivos [ser haitiano da classe média, mesmo assim chegar ao Brasil sem dinheiro] e [criticar a forma como o europeu trata o imigrante, mesmo assim ter de agir 
igualmente], aos quais se associam respectivamente os aspectos PERTENCER À CLASSE MÉDIA PT TER DIFICULDADE FINANCEIRA e NEG-SER EXEMPLO PT IGUALAR-SE. É possível verificar que este último encadeamento argumentativo reforça a ideia de que a atual imigração de haitianos é negativa para o Brasil, razão pela qual é possível pensar, como solução para o problema abordado, na ideia de os brasileiros começarem a recepcionar imigrantes como os europeus não mais de maneira receptiva. Nessa direção, é importante salientar que a própria proposta de redação orienta para uma argumentação transgressiva. Caso o aluno optasse por defender, em seu texto, o sentido constituído pelo último aspecto expresso, haveria, sem dúvida, demonstrado satisfatória competência de leitura. Em hipótese alguma, portanto, poderia perder pontos por sua argumentação, e, menos ainda, ela poderia ser julgada como fuga ao tema. Restaria ao aluno, com isso, posicionar-se favorável ou contrariamente a essa ideia.

\section{Trilha da Costura}

Os imigrantes bolivianos, pelo último censo, são mais de 3 milhões, com população de aproximadamente 9.119 milhões de pessoas. A Bolívia em termos de IDH ocupa a posição de $114^{\circ}$ de acordo com os parâmetros estabelecidos pela ONU. O país está no centro da América do Sul e é o mais pobre, sendo $70 \%$ da população considerada miserável. Os principais países para onde os bolivianos imigrantes dirigem-se são: Argentina, Brasil, Espanha e Estados Unidos.

Assim sendo, este é o quadro social em que se encontra a maioria da população da Bolívia, estes dados já demonstram que as motivações do fluxo de imigração não são políticas, mas econômicas. Como a maioria da população tem baixa qualificação, os trabalhos artesanais, culturais, de campo e de costura são os de mais fácil acesso. (OLIVEIRA, R. T. [...]). (GUIA DO ESTUDANTE, 2014).

Esse texto, embora faça constatações de dados relativos à Bolívia e aos imigrantes bolivianos, também permite evocar os encadeamentos argumentativos seguintes: [estar no centro da América do Sul, mesmo assim ser o país mais pobre, com $70 \%$ da população miserável], [não ser política a 
motivação do fluxo de imigração, mesmo assim ser econômica] e [ter baixa qualificação, portanto fazer trabalho artesanal, cultural, de campo e de costura], aos quais se associam, respectivamente, os aspectos argumentativos ESTAR NO CENTRO PT SER POBRE, NEG-IMIGRAÇÃO POLÍTICA PT IMIGRAÇÃO e TER BAIXA QUALIFICAÇÃO DC FAZER TRABALHO DO SETOR PRIMÁRIO.

Analisados os três textos motivadores que compõem a proposta de redação, organiza-se, aqui, um percurso argumentativo possível de ser utilizado pelo aluno, em sua dissertação e que pode ser considerado eficiente, sobretudo pelo fato de, além de reconhecer aspectos argumentativos normativos, que relacionam princípios de senso comum, consegue transgredi-los. No entanto, a fim de que se possa construir um texto dissertativo-argumentativo excelente no Enem, que esteja suficientemente qualificado para obter nota máxima, é preciso, evidentemente, que outros critérios também sejam atendidos por exemplo, os itens apresentados no primeiro trecho da proposta de redação entre outros, os relativos ao estilo de linguagem, aos critérios de textualidade, como a coesão e a coerência, e a explicitação de uma proposta de intervenção social, que respeite os direitos humanos. Nessa direção, é importante frisar que este trabalho não se destina a explicitar orientações a respeito desses critérios, tampouco visa a desvelar uma fórmula a ser aplicada para se construir textos dissertativo-argumentativos nota mil. O que se busca, aqui, é apresentar um percurso argumentativo possível de se realizar na redação e que esteja amparado, sobretudo, nas relações semânticas de conversão e/ou de transposição existentes entre os aspectos argumentativos dos blocos semânticos presentes nos textos motivadores.

Para tanto, vale retomar, ainda, o tema sobre o qual o aluno deveria redigir seu texto $O$ movimento imigratório para o Brasil no século XXI e os aspectos argumentativos principais associados a encadeamentos argumentativos dos textos motivadores, acrescidos dos outros aspectos de seus respectivos blocos semânticos. Confiram-se: 
(1) imigrar PT

Neg-desenvolver

(3) Neg-imigrar DC

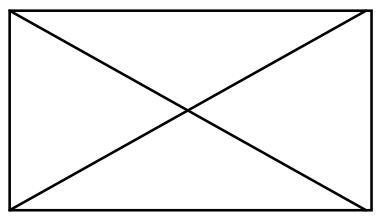

Neg-desenvolver
(2) Neg-imigrar PT desenvolver

(4) imigrar DC desenvolver

Fonte: Os autores.

Figura 2 - Bloco semântico que relaciona imigrar e desenvolver

(1) providenciar água e alimento PT Neg-providenciar abrigo

(3) Neg-imigrar DC Neg-desenvolver

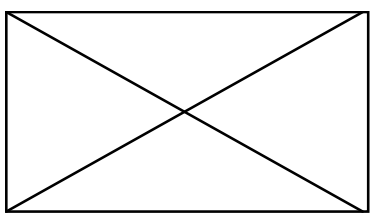

(2) Neg-viabilizar água e alimento PT providenciar abrigo

(4) viabilizar água e alimento DC providenciar abrigo

Fonte: Os autores.

Figura 3 - Bloco semântico que relaciona viabilizar água e alimento e providenciar abrigo

(1) ser exemplo PT

Neg-igualar-se

(3) Neg-ser exemplo DC

Neg-igualar-se
(2) Neg-ser exemplo PT igualar-se

(4) ser exemplo DC igualar-se

Fonte: Os autores

Figura 4-Bloco semântico que relaciona ser exemplo e igualar-se 
$\mathrm{Na}$ introdução da redação, o aluno poderia, por exemplo, colocar em evidência o sentido construído no enunciado de $\mathrm{X}$ mas também $\mathrm{Y}$ : [a história da migração humana deve ser encarada não só como uma questão relacionada ao passado mas também ao presente, tratando sobre deslocamentos recentes] apresentando, por meio de uma tese, a relevância de se discutir sobre os deslocamentos para o Brasil no século XXI.

Observados os aspectos argumentativos de blocos semânticos presentes nos textos, poder-se-ia sugerir que o estudante começasse a desenvolver sua redação reconhecendo aspectos positivos e negativos da imigração dos séculos XIX e XX, isto é, seria importante reconhecer também o aspecto IMIGRAR PT NEG-DESENVOLVER, explicitando exemplos. Contudo, seria essencial deixar claro que a imigração do passado foi, em geral, positiva para o Brasil, como bem defende a argumentação apresentada no primeiro texto motivador. Para isso, poderia fazer uso da estratégia de concessão, que, inclusive, permitiria melhor seu ethos.

Para que melhor se possa compreender como a estratégia concessiva poderia ser utilizada, a partir da proposta de redação em análise, imaginemse primeiramente argumentos favoráveis à imigração para o Brasil no século XXI, por exemplo: (1) Os movimentos imigratórios são sempre positivos para um país e (2) Não é uma forma humana deixar de tratar os imigrantes com cordialidade, como fazem muitos europeus. Explicitados dois argumentos que poderiam contrariar a argumentação de um locutor que quisesse posicionar-se contrariamente à imigração para o Brasil no século XXI, poder-se-ia desenvolver, por exemplo, um parágrafo dissertativo-argumentativo como segue:

Embora os movimentos imigratórios tenham, em geral, muitos aspectos positivos para agregar a um país e ainda que a forma de os europeus tratarem seus imigrantes não deva servir de modelo a países como Brasil, tem-se feito necessário ao "País de Todos" um maior rigor na fiscalização de entrada de imigrantes, sobretudo por meio da normatização de critérios semelhantes aos de países desenvolvidos, a fim de impedir que entrem, no Brasil, imigrantes sem estrutura mínima de sobrevivência e sem perspectivas de futuro para participar ativamente da sociedade brasileira. Em vista disso, se os movimentos imigratórios para o Brasil no século XXI pouco se assemelharem aos dos séculos XIX e XX, ser-lhe-ão evidentemente inviáveis. 
Posteriormente, seria possível discutir a respeito do aspecto do bloco semântico (2), VIABILIZAR ÁGUA E ALIMENTO PT NEGPROVIDENCIAR ABRIGO, o qual, no contexto em que está inserido, constitui a AI de negligência. Para tanto, o aluno poderia utilizar aspectos do mesmo bloco semântico, para refletir sobre a pertinência de o governo apenas disponibilizar água e alimento para os imigrantes e de se omitir a lhes providenciar abrigo. Ademais, por ser também importante tratar de aspectos do bloco semântico (3), pode-se dizer que, fazendo-se uso da estratégia argumentativa concessiva, acima apresentada, explicitar-se-ia com ela posicionamento relacionado ao aspecto argumentativo NEG-SER EXEMPLO PT IGUALAR-SE, que, de certa forma, apresentaria uma solução para o problema abordado, a partir de argumentação autorizada pela proposta de redação.

Por fim, pode-se constatar que, apresentando um percurso argumentativo dessa natureza, o aluno revelaria não apenas ter compreendido satisfatoriamente os textos motivadores da proposta de redação, mas também ter capacidade para apresentar proposta de solução ao problema em questão, com respeito aos direitos humanos. Além disso, deixaria um ethos favorável de si no discurso, isto é, constituiria uma imagem de alguém que aceita a discussão, que não procura impor-se brutalmente, visto que a concessão por permitir assumir os argumentos contrários à conclusão a que se visa é, nas palavras de Ducrot (2009), uma estratégia que possui destaque no discurso persuasivo.

Por conseguinte, pode-se constatar que, baseado em ferramentas da ADL/TBS, o estudante teria chances de constituir, em seu texto, encadeamentos argumentativos em PT, mais convincentes do que os em DC, por permitirem sair do discurso generalizante. Para melhor esclarecer a necessidade que há em conduzir os estudantes do ensino médio a realizar a leitura e a escrita de textos de maneira mais crítica, podem-se observar as conclusões a que chegou Barbisan (2005) em estudo realizado sobre a produção de discursos argumentativos na escola. A partir da análise de cem redações de vestibular, a autora diagnosticou que a transgressão de um mesmo princípio é ignorada na quase totalidade dos trabalhos, constatando a incidência de $82 \%$ de encadeamentos normativos em DC (= portanto), nos textos dos vestibulandos. 
Dados como esse citado não podem apenas apontar uma fragilidade educacional, mas devem servir de alerta, principalmente para os professores que trabalham com Língua Portuguesa, os quais podem encontrar, em pesquisas recentes da área de linguística, subsídios teóricos que evidenciam permitir qualificar a produção textual escrita dos estudantes.

\section{Conclusão}

O ensino de leitura e de produção de textos é de fundamental importância para a formação integral do aluno. Por esse motivo, nota-se um grande volume de trabalhos resultados de pesquisas que buscam aprimorar o ensino da produção de sentido e de escritura de textos no âmbito escolar. É nessa orientação que este trabalho se inscreve, ao adotar como tarefa apresentar um subsídio teórico eficaz no auxílio da produção de textos dissertativo-argumentativos. Para esse fim, partiu-se da leitura da proposta de redação da prova do Enem 2012 e mostrou-se que os textos motivadores ali presentes apontam percursos argumentativos possíveis de guiar a produção textual do aluno candidato. O fundamento teórico adotado foi a teoria da Argumentação na Língua, em sua fase da Teoria dos Blocos Semânticos, segundo a qual o sentido de um discurso se dá pela relação entre as entidades linguísticas que o constituem, sentido traduzido por meio de encadeamentos argumentativos normativos em portanto e transgressivos em mesmo assim. Os textos motivadores foram descritos semanticamente e os encadeamentos resultantes dessas análises propiciam ao aluno a produção de um texto argumentativo coerente com a proposta do exame. Além disso, a aplicação dos fundamentos teóricos aqui apresentados instrumentaliza o aluno em termos de adoção de estratégias argumentativas mais originais, como a concessão, como um meio para expressar um posicionamento original, evitando as generalidades e o senso comum. 


\section{Referências}

BARBISAN, L. B. A produção de discursos argumentativos na escola. Desenredo, Passo Fundo, v. 1, p. 69-76, jul./dez. 2005.

CAREL, M. Pourtant: argumentation by exception. Journal of Pragmatics, v. 24, p. 167-188, 1995.

CAREL, M. O que é argumentar? Desenredo, Passo Fundo, v. 1, n. 2, p. 77-84, jul./dez. 2005.

CAREL, M. Introduction. In: CAREL, M. (Org.). Argumentation et polyphonie: de Saint Augustin à Robbe-Grillet. Paris: L'Harmattan, 2012. p. 7-58.

CAREL, M.; DUCROT, O. La semántica argumentativa: una introducción a la teoría de los bloques semánticos. Tradução María Marta Negroni; Alfredo M. Lescano. Buenos Aires: Colihue, 2005.

DUCROT, O. O dizere e o dito. Revisão técnica da tradução Eduardo Guimarães. Campinas: Pontes, 1984.

DUCROT, O. Polifonía y argumentación. Cali: Universidad del Valle, 1990.

DUCROT, O. Argumentação retórica e argumentação lingüística. Letras de Hoje, Porto Alegre, v. 44, n. 1, p. 20-25, jan./mar. 2009.

GRAEFF, T. F. A conexão entre os enunciados no texto com base na semântica argumentativa. Desenredo, v. 8, n. 2, p. 197-208, jul./dez. 2012.

GRAEFF, T. F.; GOMES, L.. De prática discursiva a um novo gênero: proposta de redação. In: SEMINÁRIO NACIONAL DE LÍNGUA E LITERATURA: Teoria e Prática - Diálogos em Discursos, 4., 2012, Passo Fundo. Anais... Passo Fundo: UPF, 2012. p. 1-10.

GUIA DO ESTUDANTE. Nova proposta de redação: Enem 2012. 21 mar. 2014. Disponível em: <http://bit.do/bFasF>. Acesso em: 15 ago. 2014. 
INSTITUTO NACIONAL DE ESTUDOS E PESQUISAS EDUCACIONAIS ANÍSIO TEIXEIRA - INEP. A redação no Enem 2013: Guia do Participante. Brasília-DF, 2013.

SAUSSURE, F. de. Escritos de lingüística geral. Tradução Carlos Augusto Leuba Salum; Ana Lucia Franco. São Paulo: Cultrix, 2004. (Organizados e editados por Simon Bouquet e Rudolf Engler).

Recebido em: 29/05/2015

Aceito: $10 / 11 / 2015$ 